\title{
Corrigendum to The Need for Strategic Development of Safety Sciences
}

\author{
Francois Busquet ${ }^{1}$ and Thomas Hartung ${ }^{1,2}$ \\ ${ }^{1}$ Center for Alternatives to Animal Testing, CAAT-Europe, University of Konstanz, Konstanz, Germany; ${ }^{2}$ Johns Hopkins \\ Bloomberg School of Public Health, Center for Alternatives to Animal Testing, Baltimore, MD, USA
}

We have been alerted by chair of the EU-ANSA (the EU Agencies Network for Scientific Advice), Dr Derek Knight, ECHA, that in this manuscript, which appeared in ALTEX (2017), 34(1), 3-21, https://doi.org/10.14573/1701031, footnote 54 is to the website of the EU Agencies Network (https://euagencies. eu/), not to EU-ANSA. The EU-ANSA is a subnetwork of the EU Agencies Network. We would like to replace footnote 54 with a link he provided.

He further clarified: "The EU-ANSA was set up by the EU Agencies Network in 2013, not by the former Chief Scientific Advisor (CSA), although Professor Glover was supportive of the EU-ANSA \& she or a representative from her office attended some meetings. Hence the cessation of the CSA was not relevant to the continuation of the EU-ANSA. Nevertheless, there was a smooth transition for the EU-ANSA in networking with the Scientific Advice Mechanism (SAM) unit that superseded the CSA. To be clear on this point, the EU-ANSA is entirely independent of the CSA \& the SAM. Finally note that the EU-ANSA is not the mechanism for ECHA \& EFSA to co-ordinate, although both ECHA \& EFSA are member Agencies of the EU-ANSA. However, there is a memorandum of understanding between ECHA \& EFSA" (https://echa.europa.eu/documents/10162/13606/mou echa_efsa_en.pdf/b893fd32-a53d-41d8-aef4-29d97db81df4).
In order to correct this, we would like to change the paragraph that runs from page 15 to 16 in Section 4.2:

Noteworthy, both European agencies most recently have started a discussion toward strategic planning including the tools and ways safety assessments should be done. This represents a major change from their former more receiving and executing roles. It is not clear how much of this change is harmonized and coordinated, e.g., by the Agency Network Scientific Advice $\underline{54}$ (ANSA), but they appear rather independent. ANSA is a recently established structure that organizes face-to-face meetings that take place once a year at rotating locations. It was initiate the CSA created in order to share "good practices" and harmonize working vocabulary such as "independent", etc. The network has survived the CSA's termination and was renamed The EU Ageney Network 54 . EU-ANSA is not the mechanism for ECHA and EFSA to co-ordinate bilaterally, however, there is a memorandum of understanding between the agencies. It is worth mentioning that such steering already existed from 2006 to 2011 but was terminated by the EC.

54 https://www.efsa.europa.eu/sites/default/files/corporate_publications/euansa150809en.pdf

https://doi.org/10.14573/altex.1703281 